glass is not due to the presence of lichens but the undoubted growth of lichens on it is due to, and subsequent to, the glass being decayed.

The immediate cause of decay and the formation of the characteristic pit holes is surely due to chemical and physical decomposition, and it is only when the glass is in an advanced state of decay that the lichens find in the disintegrated glass accumulated in the pits a soil suitable for their growth. (For details I would refer to an article in NATURE of May 2, I907.)

One finds, in fact, that the degree and character of the corrosion is determined by the chemical composition of the glass. The statement that the glass of the twelfth to the fifteenth century shows a slower rate of alteration than that used later needs some modification. The glass of the twelfth century was of good quality and shows little decay, but there was steady deterioration from the thirteenth to the beginning of the fifteenth century; the glass of this latter period shows the most pronounced decay. After this time the composition of the glass in general steadily improved.

The point I would particularly challenge, however, is the suggestion that windows should be treated with a liquid mastic to prevent the growth of lichens. I am not quite sure if this is intended to apply to new or old windows. If the latter, surely the remedy is a thousand times worse than the disease. If the former, I suggest that the proper way to prevent the growth of lichens is to prevent the decay of the glass which enables them to gain a foothold. That can be done only by ensuring that glass of a composition which ensures durability is used in new windows. As a matter of fact the glass used nowadays as a rule leaves little to be desired in this respect.

One further point occurs to me. I have made many analyses of medieval stained glass and I invariably find phosphates as a constituentparticularly in glass of the fourteenth century. As the glass decays this would presumably be deposited as calcium phosphate in the corrosion pits. Would this encourage the subsequent growth of lichens and account in some measure for the prolific flora described by Dr. Mellor?

8I Queen Victoria Street, E.C:4 August 29.

THE article referred to by Mr. Noël Heaton describes the results of " one of several possible lines of research" ; it shows that lichens accelerate the chemical change of the glass and lead, and exert a mechanical action on the altered glass.

Certain species of lichen are found only on unaltered glass; they do not persist, and on disappearing leave a roughened surface conformable to their own shape. On deeply corroded glass, lichen débris, not the plant, is the more frequent. Lichen physiology is a controversial subject, but the probability is that neither the calcium phosphate nor the "soil" mentioned by Mr. Heaton accounts for the flora.

References to the presence of three species of lichen on the windows of two churches are made by Fries and Nylander, and reproduced by a few lichenologues; there has been, to my knowledge, no scientific investigation of the lichen flora on church windows or of its relation to the deterioration of glass until three years ago when the research was undertaken at the Sorbonne. I cannot therefore appreciate Mr. Heaton's statement that it " has frequently been suggested " that " the decay of ancient stained glass is produced by the action of lichens." I am, however, open to correction if Mr. Heaton will give the authority for his statement.
The only modification I can make with regard to the glass of the twelfth to the fifteenth centuries is that certain glass of the twelfth century is immune, but is this not to some extent true of the glass of each century? It is reassuring to be told that "the glass used nowadays as a rule leaves little to be desired " as regards durability, when one knows that certain stained glass of so recent a date as the second half of the nineteenth century shows an advanced state of corrosion. In this case lichens have apparently played no part.

The quality of the glass is undoubtedly a factor of great importance in ensuring its durability, but it cannot prevent the growth of lichens, as some of these plants find a suitable substratum on the smooth unaltered surface of the glass. The application of a liquid mastic to exclude the lichen spores is intended for those windows difficult of access for cleaning purposes. What can be the objection to its use on old glass and not on new? The suggestion is not my own; it finds favour with one who has more than forty years' experience in the art of stained glass, medieval and modern, and has the keenest appreciation of æsthetic value.

It may be mentioned that the destructive effect of lichens on their substratum is remarkably evident on the marble statues at Versailles,-some eighteen months ago it was decided to arrest the corrosion by cleaning the marble and then treating it with a mastic.

Does Mr. Heaton use the word "disease" in its popular or pathological sense? It is to my mind as wrongly used in connexion with the corroded glass as it would be if applied to the weathering and disintegration of rocks.

Through the courtesy of Mr. J. A. Knowles, of York, I have had access to Mr. Knowles's own work and once more read Mr. Noël Heaton's papers on the composition and decay of glass. I see no inconsistency between these papers and my article in NATURE of August 25.

University College, Reading. September I 5 .

\section{Painted Pebbles from the North-East Coast of Scotland.}

THE statement that Azilian painted pebbles do not occur further north than Basle was made by me in a review appearing in NATURE, August 25, p. 276. It has been challenged and the so-called painted pebbles found by Sir F. Tress Barry on the N.E. coast of Scotland recalled. These interesting objects cannot, however, be referred to the Azilian culture, and this for two reasons, namely :

(I) They were found in connexion with and in the precincts of Broch buildings, admittedly from their archæological and faunal content of much later date. It has been suggested that the Broch had been constructed on an older Azilian settlement, but this idea is vetoed by,

(2) When the actual objects are seen and handled it is found they in no respect resemble the Azilian painted pebbles. Prof. H. Breuil, of Paris-previously a partisan of the early age for these objectsat once rejected the Azilian date on seeing the specimens. I may add that I also came to the same conclusion when I saw and handled the-stones.

However, it need not be added that the above in no way detracts from the interest of these queer objects from the Broch, and the problem of their meaning and object still remains unsolved.

M. C. B.

$$
\text { NO. } 28 \text { I } 4 \text {, VOL. I I } 2]
$$

